\title{
The Infra-Red Absorption Spectrum of Diborane
}

\author{
W. E. Anderson* and E. F. Barker \\ Randall Laboratory of Physics, University of Michigan, Ann Arbor, Michigan
}

(Received January 3, 1950)

\begin{abstract}
The infra-red absorption spectrum of diborane has been examined under high resolution from $3.7 \mu$ to $30 \mu$ with automatic recording grating spectrometers. The rotational fine structure in two bands of each of the three types characteristic of asymmetric top molecules has been measured. All results and observations are consistent with the conclusion that diborane has the bridge structure, and belongs to the same symmetry point group, $V_{h}$, as ethylene. The observation and structure of the band with center at $368.7 \mathrm{~cm}^{-1}$ provides spectroscopic evidence that the molecule is non-planar, and makes more definite the assignment of fundamental frequencies. Data on all bands fit quite well the symmetric top. approximation, since accidentally two principal moments of inertia are approximately the same, and calculations yield accurate values for certain rotational constants.
\end{abstract}

\section{INTRODUCTION}

$\mathrm{D}$ IBORANE is a so-called "electron deficient" molecule for which the structure has been under discussion for a long time. Stitt ${ }^{1}$ made a study of the infra-red spectrum from $1.7 \mu$ to $25 \mu$ with a prism spectrometer, and attempted to explain the results on the basis of an ethane-type structure. Bell and LonguetHiggins $^{2}$ gave a normal coordinate treatment for the bridge model, and made an identification of the absorption bands observed by Stitt with the normal vibrations. Price ${ }^{3}$ re-examined the infra-red absorption spectrum using a prism spectrometer capable of resolving some of the rotational fine structure of two bands. His results indicate decisively that the bridge model, symmetry point group $V_{h}$, is favored over the ethane-type structure, symmetry point group $D_{3 d}$ or $D_{3 h}$.

Examination of the infra-red absorption spectrum has now been made from $3.7 \mu$ to $30 \mu$ with high resolution grating spectrometers. The rotational fine structures of six bands have been resolved; fundamental frequencies can now be assigned more definitely, and certain rotational constants determined.

\section{EXPERIMENTAL}

The sample of diborane was prepared in the Chemistry Department of the University of Chicago. During the course of the investigation it was purified several times by fractionation and distillation. The appreciable quantity of ethane detected in the sample was not removed because of the difficulty of the separation and the fact that the strong bands of ethane and diborane do not overlap.

The principal instrument used was the grating spectrometer with potassium bromide foreprism originally described by Hardy, ${ }^{4}$ but modified in this study for automatic recording. The radiation beam from a Nernst glower was chopped with a period of about eight

* Present address: The Citadel, Charleston, South Carolina.

${ }^{1}$ F. Stitt, J. Chem. Phys. 9, 780 (1941).

2 R. P. Bell and H. C. Longuet-Higgins, Proc. Roy. Soc. 183A, 357 (1945).

${ }^{3}$ W. C. Price, J. Chem. Phys. 16, 894 (1948).

${ }^{4}$ J. D. Hardy, Phys. Rev. 38, 2162 (1931). seconds, and received on a single-junction thermocouple of the usual Michigan design. The Firestone-type amplifier ${ }^{5}$ was followed by several stages of electronic amplification, diode rectifiers, and $R C$ filters so that only the envelope of the individual rotational lines was traced by the Speedomax recorder. With the exception of Fig. 5, photographs of band records shown were taken directly from charts made by the recorder pen on tracing paper. The design of the Firestone amplifier and the electronic amplifying system involved circuits with long time constants, and accordingly required slow rotation of gratings, but precluded drifts from temperature changes and other common causes.

The grating-instrument constants for the fine gratings were determined from records made in several orders of $1.014 \mu$ line of mercury or the $1.083 \mu$ line of helium. For the coarse gratings, secondary standard lines in the absorption spectra of atmospheric $\mathrm{CO}_{2}$ near $14.7 \mu$ and $\mathrm{H}_{2} \mathrm{O}$ vapor near $6.0 \mu$ were used, the positions of these lines having been very accurately measured in this laboratory. ${ }^{6}$

To observe the diborane absorption band in the region from $22.5 \mu$ to $30 \mu$, it was necessary to use the long wave-length vacuum spectrograph of large aperture developed by Randall and Firestone. ${ }^{7}$ In this instrument which uses photographic recording, overlapping of higher orders of short wave-lengths was prevented by using a $\mathrm{NaCl}$ shutter, paraffin wax filter and one reflection from a $\mathrm{CaF}_{2}$ plate. The energy available in the region from $27 \mu$ to $30 \mu$ is greatly reduced by the poor transmission of materials mechanically strong enough to serve as cell windows, which must withstand atmospheric pressure in the arrangement employed. The cell used in this instrument was of silverplated brass, $10 \mathrm{~cm}$ long, with silver chloride windows $1 \mathrm{~mm}$ thick, one of which had to be about 15 by 10 centimeters to prevent serious limitation of the radiation beam behind the exit slit where it was mounted. The instability of diborane requires that it be kept in a vessel which

${ }^{5}$ F. A. Firestone, Rev. Sci. Inst. 3, 163 (1932).

${ }^{6}$ R. H. Gillete and E. H. Eyster, Phys. Rev. 56, 1113 (1939).

${ }^{7}$ H. M. Randall and F. A. Firestone, Rev. Sci. Inst. 9, 40 (1938). 
TABLE I. Experimental conditions.

\begin{tabular}{ccccc}
\hline $\begin{array}{c}\text { Region } \\
\text { microns }\end{array}$ & $\begin{array}{c}\text { Grating or } \\
\text { prism }\end{array}$ & $\begin{array}{c}\text { Cell length } \\
\mathrm{cm}\end{array}$ & $\begin{array}{c}\text { Slit width } \\
\mathrm{cm}^{-1}\end{array}$ & $\begin{array}{c}\text { Gas pressure } \\
\mathrm{mm} \mathrm{Hg}\end{array}$ \\
\hline 2.71 & Quartz & 10 & $(\mathrm{a})$ & 120 \\
3.83 & 7200 & 12 & 0.58 & 6 \\
3.83 & 7200 & 12 & 0.72 & 24 \\
3.97 & 7200 & 12 & 0.67 & 15 \\
4.26 & $\mathrm{LiF}$ & 10 & $(\mathrm{a})$ & 196 \\
5.02 & 7200 & 12 & 0.48 & 456 \\
5.02 & 4800 & 12 & 0.75 & 560 \\
5.38 & 7200 & 12 & 0.46 & 74 \\
5.38 & $\mathrm{LiF}$ & 10 & $(\mathrm{a})$ & 35 \\
6.26 & $\mathrm{NaCl}$ & 10 & $(\mathrm{a})$ & 6 \\
8.52 & 2400 & 12 & 0.46 & 20 \\
10.28 & 2400 & 12 & 0.46 & 75 \\
27.16 & 1200 & 12 & 0.92 & 46 \\
27.16 & 900 & 10 & 2.22 & 100 \\
\hline
\end{tabular}

a Slit widths continuously varied.

can be evacuated to the order of $10^{-4} \mathrm{~mm}$ of $\mathrm{Hg}$ pressure. Beyond $30 \mu$ there was insufficient energy transmitted by the silver chloride to permit consistent measurements even with relatively wide slits and maximum gain of the amplifier used.

The vacuum prism spectrograph described most recently by Oetjen ${ }^{8}$ was used to examine the envelope of several bands which are overlapped by strong atmospheric absorptions.

A summary of experimental conditions is given in Table I.

\section{ASSIGNMENT OF FREQUENCIES}

The normal vibrations on the bridge model according to Bell and Longuet-Higgins ${ }^{2}$ are given in Fig. 1, where the frequency designations shown are those based on the discussion which follows. These designations differ in certain aspects from those given in references 2 and 3 . Because of the extensive tables and other material on symmetry point group $V_{h}$, and especially on ethylene, given by Herzberg, ${ }^{9}$ it has seemed desirable to designate the axes of reference in the molecule in conformity with those adopted for ethylene. This designation of axes requires interchanging subscripts 1 and 2 in the symbols for symmetry species of the normal vibrations as given by Price, ${ }^{3}$ and requires renumbering of nine of the eighteen fundamentals to conform to this convention. ${ }^{10}$ Either designation is consistent, but because of the almost complete similarity of the spectra, confusion is liable to result if different schemes are used for diborane and ethylene. In consequence of these variations from Price's notation and other changes in assignments, the designations by Price $^{3}$ are included in Table II, which summarizes the fundamental frequency assignments. The vacuum correction has been applied to all wave number values.

When observed under high resolution the diborane spectrum reveals three distinct types of bands. These

\footnotetext{
${ }^{8}$ Oetjen, Kao, and Randall, Rev. Sci. Inst. 13, 515 (1942).

${ }^{9}$ G. Herzberg, Infrared and Raman Spectra (D. Van Nostrand Company, Inc., New York, 1945).

${ }^{10}$ Reference 9, pp. 107, 272.
}

TABLE II. Fundamental frequencies of diborane.*

\begin{tabular}{|c|c|c|c|c|}
\hline \multirow[b]{2}{*}{ Species } & \multirow[b]{2}{*}{ Band type } & \multicolumn{2}{|c|}{ Designation } & \multirow{2}{*}{$\begin{array}{c}\text { Frequency } \\
\mathrm{cm}^{-1}\end{array}$} \\
\hline & & Revised & Price** & \\
\hline \multirow{4}{*}{$a_{g}$} & $R$ & $\nu_{1}$ & & 2523 \\
\hline & $R$ & $\nu_{2}$ & & 2102 \\
\hline & $R$ & $\nu_{3}$ & & 1180 \\
\hline & $R$ & $y_{4}$ & & 793 \\
\hline \multirow{3}{*}{$\begin{array}{l}a_{u} \\
b_{10}\end{array}$} & $R$ & $\nu_{5}$ & & $1013^{a}$ \\
\hline & $R$ & $\nu_{6}$ & $b_{2 \sigma} \nu_{11}$ & $2591^{\mathrm{a}}$ \\
\hline & $R$ & $\nu_{7}$ & $b_{2 g} \nu_{12}$ & $606^{\mathrm{a}}$ \\
\hline \multirow[t]{2}{*}{$b_{1 u}$} & $I R C$ & $\nu_{8}$ & $b_{2 u} \nu_{13}$ & 1988.0 \\
\hline & $I R C$ & $\nu_{9}$ & $b_{2 u} \nu_{14}$ & 972.7 \\
\hline \multirow[t]{2}{*}{$b_{2 g}$} & $R$ & $\nu_{10}$ & $b_{1 g} \nu_{6}$ & $1321^{\mathrm{s}}$ \\
\hline & $R$ & $\nu_{11}$ & $b_{1 g} \nu_{7}$ & $764^{a}$ \\
\hline \multirow[t]{3}{*}{$b_{2 u}$} & $I R B$ & $\nu_{12}$ & $b_{1 u} \nu_{8}$ & 2608.6 \\
\hline & $I R B$ & $\nu_{13}$ & $b_{1 u} \nu_{10}$ & 1857 \\
\hline & $I R B$ & $\nu_{14}$ & $b_{\mathrm{t} u} \nu_{9}$ & 368.7 \\
\hline \multirow{4}{*}{$\begin{array}{l}b_{3 a} \\
b_{3 u}\end{array}$} & $R$ & $\nu_{15}$ & & $1745^{\mathrm{a}}$ \\
\hline & $I R A$ & $\nu_{16}$ & & 2519.5 \\
\hline & $I R A$ & $\nu_{17}$ & & $1604^{b}$ \\
\hline & $I R A$ & $\nu_{18}$ & & 1173.8 \\
\hline
\end{tabular}

* $R$ : Raman active; $I R$ : Infra-red active. Raman frequencies from data on liquid diborane (references 12 and 13 ).

** See reference 3

From data of Pitzer (reference 13).

b From data of Price (reference 3 ).

are designated as type $A$, type $B$, and type $C$, depending on the direction of variation of the electric moment along the axis of least, intermediate, or greatest moment of inertia, respectively. Since the well-resolved bands include two of each of these three types characteristic of an asymmetric top molecule, and since an exact counterpart of these bands can be found among the similarly resolved bands of ethylene for those vibrations not essentially involving the bridge hydrogens, the validity of the bridge structure seems definitely estab-
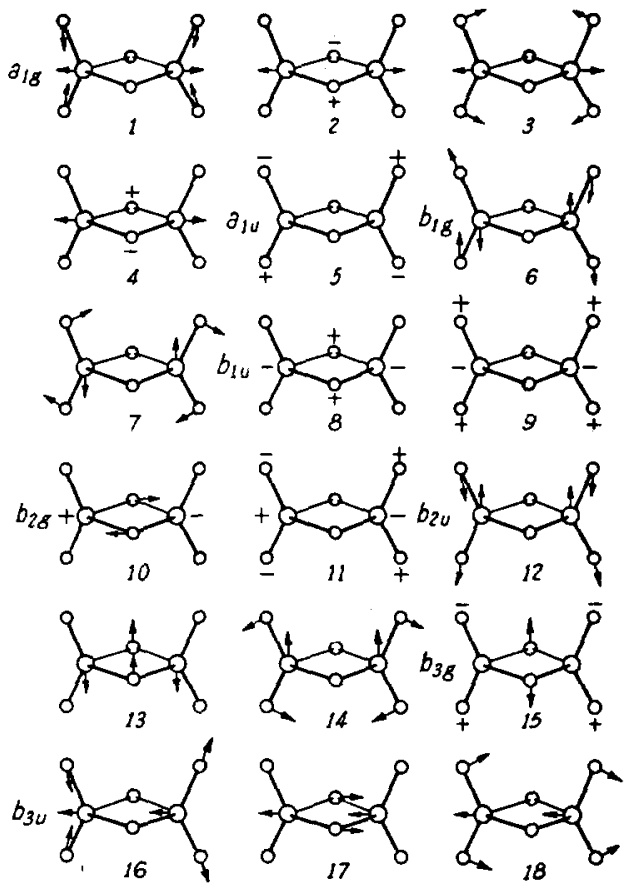

FIG. 1. Normal vibrations of diborane, $\mathbf{B}_{2} \mathbf{H}_{6}$ (Bell and Longuet-Higgins, reference 2.) 


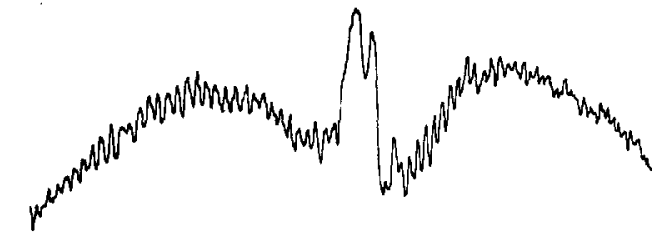

2480 ' 2500 ' $25^{\prime} 20$ ' $25^{\prime} 40$ ' $2560 \mathrm{~cm}^{-1}$

Frg. 2. Type $A$ band at $2519.5 \mathrm{~cm}^{-1}$. Echlette grating, 7200 lines per inch. Slit width, $0.67 \mathrm{~cm}^{-1}$. Gas pressure, $15 \mathrm{~mm}$ of $\mathrm{Hg}$.

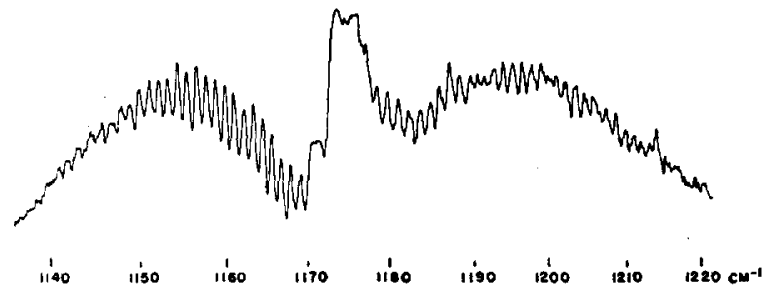

Fig. 3. Type $A$ band at $1173.8 \mathrm{~cm}^{-1}$. Echlette grating, 2400 lines per inch. Slit width, $0.46 \mathrm{~cm}^{-1}$. Pressure $20 \mathrm{~mm}$ of $\mathrm{Hg}$.

lished. Whether the infra-red data can be used to decide between planar and non-planar possibilities is discussed below. The clues for the identification of normal vibrations with observed absorption bands are found in the envelopes of the resolved bands and in the analogy with the assignments for ethylene.

The type $A$ bands at $2519.5 \mathrm{~cm}^{-1}$ and $1173.8 \mathrm{~cm}^{-1}$ are shown in Fig. 2 and Fig. 3, and are identified as such by Price $^{3}$ with $\nu_{16}$ and $\nu_{18}$ respectively. The other fundamental band corresponding to species $b_{3 u}$ is obscured by the $6.2 \mu$ water band, but records obtained with the prism spectrograph confirm the assignment made by Price of the band in this region as $\nu_{17}$.

Three prominent and strong type $B$ bands which correspond to vibrations of symmetry species $b_{2 u}$ have been observed at $2608.6 \mathrm{~cm}^{-1}, 1857 \mathrm{~cm}^{-1}$, and 368.7 $\mathrm{cm}^{-1}$, and can reasonably be assigned respectively as $\nu_{12}, \nu_{13}$, and $\nu_{14}$. Reproductions of the band at 2608.6 $\mathrm{cm}^{-1}$ are given in Fig. 4. The representation of the band at $368.7 \mathrm{~cm}^{-1}$ is shown in Fig. 5. Ordinates for this curve were obtained by dividing recorded galvanometer swings obtained with diborane in the absorption cell by the swings when the cell was evacuated. While the effects of water vapor were completely removed in each case, the large variation in transmission of the silver chloride windows over the spectral region covered made this procedure necessary in order to obtain the true shape of this band.

Observation of the band at $1857 \mathrm{~cm}^{-1}$ with automatic recording is made most difficult because of intense water vapor absorption in this region. The technique used with the grating spectrometer was to make one curve with the absorption cell filled to a suitable pressure with diborane, and one curve with the evacuated cell in the radiation beam. Frequent calibration marks were placed on each curve, and at intervals of 20 or 30 seconds of arc, deflections from the zero were measured, percent transmission calculated and plotted. The steep slopes of the water vapor lines, even when the complete record of the band was stretched out to a length of about 12 feet, made the resulting curve somewhat uncertain; consequently the rotational fine structure is too ragged to permit analysis comparable with that of the well-resolved bands. This band has also been studied with a lithium fluoride prism in the vacuum spectrograph. While it exhibits some unusual features, the shape, intensity, spectral extent, and line separation, where observable, are all consistent with its interpretation as a fundamental of species $b_{2 u}$. Also, no allowed combination seems to fit the absorption at $1857 \mathrm{~cm}^{-1}$.

Bell and Longuet-Higgins ${ }^{2}$ and Price ${ }^{3}$ assigned 412 $\mathrm{cm}^{-1}$ or $430 \mathrm{~cm}^{-1}$ respectively to the vibration shown as $\nu_{13}$. Both Price and Stitt, ${ }^{1}$ whose data Bell and Longuet-Higgins used, observed only a small part of the high frequency branch of the band centered at $368.7 \mathrm{~cm}^{-1}$, and accordingly the true character of this band has not previously been known. Observations covering the spectral region from $332 \mathrm{~cm}^{-1}$ to $480 \mathrm{~cm}^{-1}$ revealed no other bands.

The identification of the frequency $368.7 \mathrm{~cm}^{-1}$ with the motion indicated for $\nu_{14}$ instead of with that for $\nu_{13}$ is made principally by comparison with the analogous motion in $\mathrm{C}_{2} \mathrm{H}_{4}$ for which the frequency is 810 $\mathrm{cm}^{-1}$ as recently reported. ${ }^{11}$ Assignment of $1857 \mathrm{~cm}^{-1}$ or any other comparable frequency to this vibration appears unjustified, since the restoring forces are exexpected to be less in diborane than in ethylene.

Type $C$ bands correspond to the vibrations of symmetry species $b_{\mathbf{1} u}$ in which variation of the electric moment is along the axis of maximum moment of inertia. The most prominent band of this type is the absorption at $972.7 \mathrm{~cm}^{-1}$ shown in Fig. 6, which is identified with $\nu_{9}$. The other fundamental of this sym-

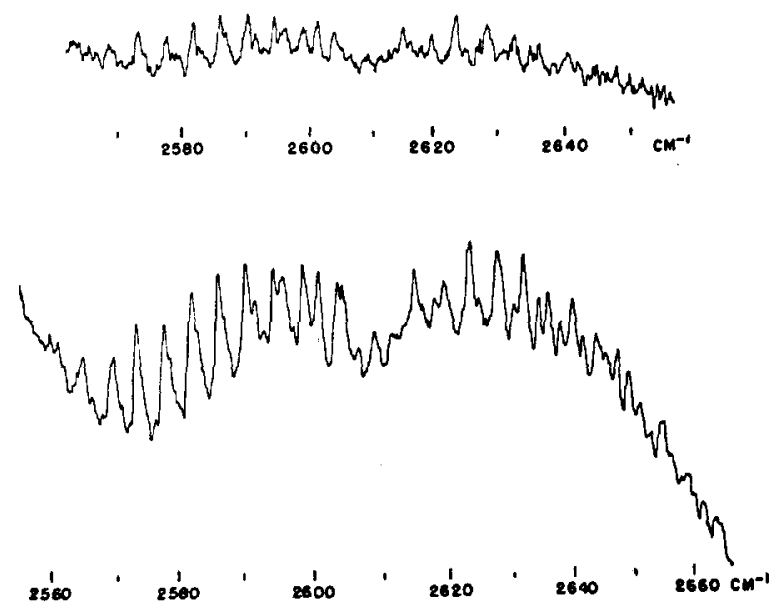

FIg. 4. Type $B$ band at $2608.6 \mathrm{~cm}^{-1}$. Echlette grating, 2400 lines per inch. Top curve: Slit width, $0.58 \mathrm{~cm}^{-1}$. Gas pressure, $6 \mathrm{~mm}$ of $\mathrm{Hg}$. Bottom curve: Slit width, $1.3 \mathrm{~cm}^{-1}$. Gas pressure, $24 \mathrm{~mm}$ of $\mathrm{Hg}$.

${ }^{11}$ B. L. Crawford, Jr., Phys. Rev. 76, 161(T) (1950). 


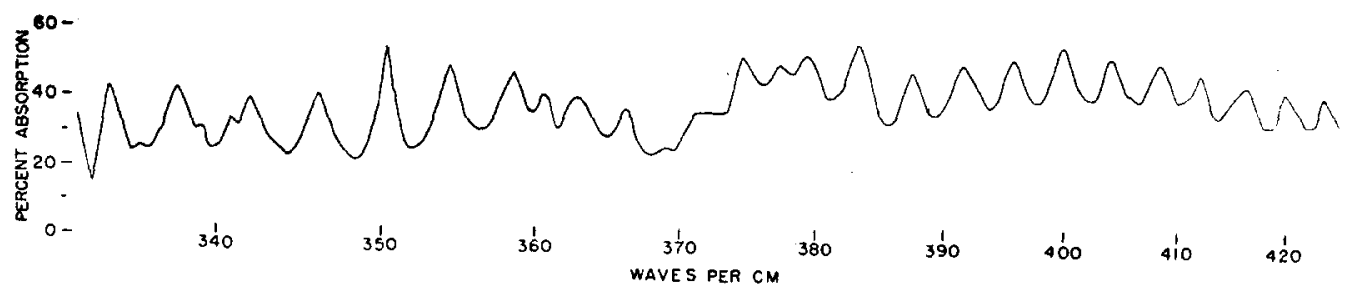

FIG. 5. Percent absorption curve of band at $368.7 \mathrm{~cm}^{-1}$. Echlette grating, 900 lines per inch. Slit width, $2.22 \mathrm{~cm}^{-1}$. Gas pressure, $100 \mathrm{~mm}$ of $\mathrm{Hg}$.

metry species appears to be the absorption of medium intensity at $1988.0 \mathrm{~cm}^{-1}$, since neither of the remaining unassigned strong absorptions has the proper characteristics. From the records made with the $\mathrm{LiF}$ prism in vacuum, the strong absorption at $2353 \mathrm{~cm}^{-1}$ is a typical band of type $A$, which can readily be accounted for as a combination band. The absorption at about $3670 \mathrm{~cm}^{-1}$ is quite strong, but observations in air fail to reveal its structure because of water vapor absorption. Moreover, both the quartz and the lithium fluoride prisms used in the vacuum spectrograph have troublesome absorptions in this region. Indications are, however, that the band is also type $A$, and several allowed combination bands of this type can be predicted for the region. The frequency $3670 \mathrm{~cm}^{-1}$ is probably too high for the fundamental vibration $\nu_{8}$ involving motion of the bridge hydrogen atoms along the axis of maximum moment of inertia.

The band at $1988.0 \mathrm{~cm}^{-1}$ is unquestionably type $C$, although here also the observations are hampered by water vapor absorptions, and plotting of percent absorption curves is necessary in order to work through some of the water lines. The rotational fine structure, however, stands out prominently enough to yield data in good agreement with measurements of the strong type $C$ band at $972.7 \mathrm{~cm}^{-1}$.

Measurements of the Raman-active frequencies for liquid diborane originally made by Anderson and Burg ${ }^{12}$ have been repeated recently by Pitzer and his associates. ${ }^{13}$ The values obtained by the latter are included in Table II for those cases where the two observations disagree. Assignments of these frequencies have been made by comparison with the frequencies in ethylene ${ }^{14}$ as modified by the recent work of Crawford, ${ }^{11}$ it being considered in general that the frequencies in diborane will be less than those in $\mathrm{C}_{2} \mathrm{H}_{4}$. The value $606 \mathrm{~cm}^{-1}$ is taken as $\nu_{7}$, since the comparable infra-red active vibration is taken as the low frequency $\nu_{14}$. (These vibrations are "in phase" and "out of phase" combinations of the $\mathrm{BH}_{2}$ rocking motion.) The frequency $1745 \mathrm{~cm}^{-1}$ was assigned as $\nu_{15}$, symmetry species $b_{3 g}$, in order to obtain possible combinations to account for certain weak bands.

The infra-red active combination bands can be calculated by using the rules set forth by Herzberg, ${ }^{15}$

\footnotetext{
12 T. F. Anderson and A. B. Burg, J. Chem. Phys. 6, 586 (1938). ${ }^{18}$ Private communication.

14 Reference 9, p. 326.

15 Reference 9, p. 126.
}

which may be summarized by stating that only combinations of levels of different symmetry species and opposite symmetry with respect to inversion at the center of symmetry will be allowed. Price ${ }^{3}$ has given assignments for many of the combination bands, but differences in assignments of fundamental frequencies used here make possible certain plausible predictions which Price was not able to make. Assignment of combination bands is given in Table III. An attempt has been made to account for the higher frequency bands which appear to involve only binary combinations of the fundamentals. The predicted band types agree generally in those cases experimentally observed by Price $^{3}$ except possibly in the region $1267-1405 \mathrm{~cm}^{-1}$ where the observations seem rather indefinite.

The selection rules and activities of vibrations which were used above apply to $\mathrm{B}_{2}{ }^{11} \mathrm{H}_{6}$ and $\mathrm{B}_{2}{ }^{10} \mathrm{H}_{6}$ of symmetry species $V_{h}$. However the molecule $\mathrm{B}^{11} \mathrm{~B}^{10} \mathrm{H}_{6}$ which is half as numerous as $\mathrm{B}_{2}{ }^{11} \mathrm{H}_{6}$ and eight times as numerous as the other possible molecule in natural diborane belongs to symmetry point group $C_{2 v}$ which has different selection rules and activities from $V_{h}$. In $\mathrm{B}^{11} \mathrm{~B}^{10} \mathrm{H}_{6}$ vibrations corresponding to species $A_{g}, B_{1 g}$, $B_{2 g}$, and $B_{3 q}$ become infra-red active with frequencies slightly increased from the values in the $\mathrm{B}_{2}{ }^{11} \mathrm{H}_{6}$ Raman spectrum because of the isotope effect. However, most of these vibrations cannot be observed since they fall within regions covered by other strong infra-red active fundamentals.

The isotope effect is apparent in all the diborane bands so far resolved except possibly the band at $27 \mu$. The central maxima (or central minima for the type $B$ bands) exhibit major and minor components with the weaker component at higher frequency as expected since $\mathrm{B}^{11} \mathrm{~B}^{10} \mathrm{H}_{6}$ has smaller mass and is only one-half as numerous as $\mathrm{B}_{2}{ }^{11} \mathrm{H}_{6}$. For the strong type $B$ and type $C$ bands which are well resolved, definite series of lines due to the two more numerous molecules may be identified.

Near the central maxima of the type $A$ bands at 2519.5 and $1173.8 \mathrm{~cm}^{-1}$, Figs. 2 and 3 , there are prominent absorption maxima which appear to be due neither to the isotope effect nor to changes in rotational energy. It seems reasonable to identify these absorption maxima with the $Q$-branches of upper stage bands. ${ }^{16}$

${ }^{16}$ Reference 9, p. 267. 


\section{DETERMINATION OF ROTATIONAL CONSTANTS}

The electron diffraction data for diborane when interpreted on the non-planar bridge model ${ }^{17}$ indicate a difference of less than 7 percent between the two larger moments of inertia. While extreme accuracy in locating the positions of hydrogen atoms is not obtained by this method it is evident that diborane is accidentally (not because of its symmetry) almost a symmetric top. Accordingly, the analysis of the rotational fine structure observed in the infra-red absorption bands can be discussed on the symmetric top approximation. The notations and relations given by Herzberg ${ }^{9}$ will be used in giving the results of this analysis.

For a slightly asymmetric prolate top such as diborane, use of the combination relations yields, in addition to the values of the band centers, the rotational constants $A=h /\left(8 \pi^{2} c I_{A}\right)$, and $\widetilde{B}=(B+C) / 2$, where $B=h /\left(8 \pi^{2} c I_{B}\right)$ and $C=h /\left(8 \pi^{2} c I_{C}\right), h$ being Planck's constant an $\mathrm{l} c$ the velocity of light in vacuum. $I_{A}, I_{B}$, and $I_{C}$ are the principal moments of inertia listed in the order of increasing magnitude. They are the so-called effective moments, which are in first approximation, linear functions of the vibrational quantum numbers due to the vibration-rotation interaction. In the analysis for the slightly asymmetric case, use of small $K$ values is avoided since lines with small $K$ are most sensitive to the deviation from a symmetric top.

Table IV shows the positions of the lines and the assigned $J$ values in the type $A$ bands (parallel bands) at 2519.6 and $1173.8 \mathrm{~cm}^{-1}$. The values of

$$
\frac{R(J-1)+P(J)}{2}
$$

for each band show so little systematic change with increasing $J$ that simple averages were used to determine the band centers. The vacuum correction has been applied in all tables.

For the band at $2519.6 \mathrm{~cm}^{-1}$ the values of $\Delta_{2} F^{\prime \prime}(J)$ and $\Delta_{2} F^{\prime}(J)$ fell almost exactly on straight lines; for the $1173.8 \mathrm{~cm}^{-1}$ band the curves leveled off somewhat with increasing value of $J$. In each case a least-squares method was used to find the best representation of straight lines to fit the plotted points. The slopes of these lines, $4 \widetilde{B}^{\prime \prime}$ and $4 \widetilde{B}^{\prime}$, were compared directly with the computed values of $\Delta_{2} F^{\prime \prime}(J) /\left(J+\frac{1}{2}\right)$ and $\Delta_{2} F^{\prime}(J) /$ $\left(J+\frac{1}{2}\right)$ to obtain the mean absolute deviations indicated in Table $\mathrm{X}$, which summarizes the rotational constants and band centers for all bands analyzed. Computations of this type form a check on the correctness of assignment of $J$ values.

For the type $A$ bands nearly every line appearing under the resolution obtained is accounted for, except those in or near the central maxima. In these type $A$ bands, in first approximation, only the subsidiary maxima adjacent to the central maxima reveal the isotope effect indicating the presence of $\mathrm{B}^{11} \mathrm{~B}^{10} \mathrm{H}_{6}$.

The analysis of the type $B$ and type $C$ bands (perpendicular bands) on the symmetric top approximation is less satisfactory, as expected. Tables $\mathrm{V}$ through IX show the line positions and the $K$ values assigned for the resolved type $B$ and type $C$ bands.

In the regions of $972.7 \mathrm{~cm}^{-1}$ and $2608.6 \mathrm{~cm}^{-1}$ the series of especially strong ${ }^{R} Q_{K}$ and ${ }^{P} Q_{K}$ lines were naturally identified with the molecules $\mathrm{B}_{2}{ }^{11} \mathrm{H}_{6}$. However, another very prominent series of lines in each of these bands may be identified as associated with the next most numerous isotopic molecule $\mathrm{B}^{11} \mathrm{~B}^{10} \mathrm{H}_{6}$. The combination relations have been applied to each of

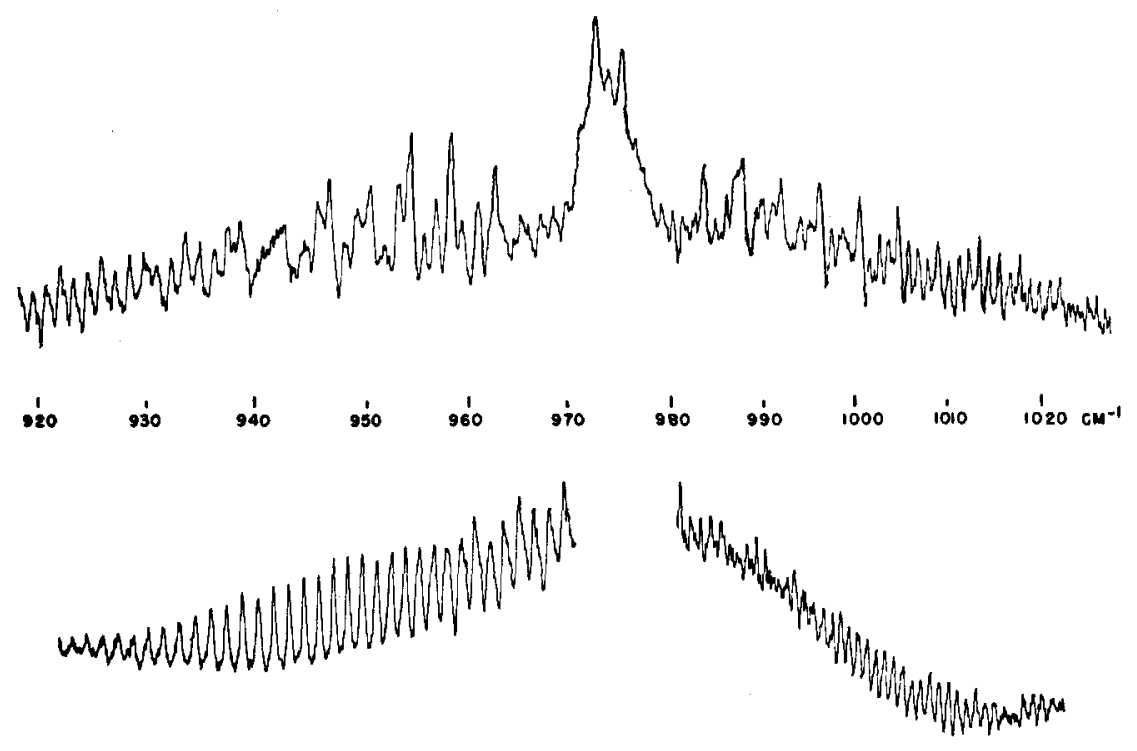

Fig. 6. Type $C$ band at $972.7 \mathrm{~cm}^{-1}$. Echlette grating, 2400 lines per inch. Top curve: Slit width, $0.46 \mathrm{~cm}^{-1}$. Gas pressure, $75 \mathrm{~mm}$ of $\mathrm{Hg}$. Bottom curves: Gas pressure, $150 \mathrm{~mm}$ of $\mathrm{Hg}$. Negative branch: slit width, $0.38 \mathrm{~cm}^{-1}$. Positive branch : slit width, $0.53 \mathrm{~cm}^{-1}$.

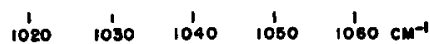

${ }^{17}$ S. H. Bauer, Chem. Rev. 31, 43 (1942). 
TABLE III. Infra-red combination bands of diborane.

\begin{tabular}{|c|c|c|c|c|c|}
\hline \multicolumn{2}{|c|}{ Observed frequency } & Intensity & Assignment & $\begin{array}{l}\text { Calcu- } \\
\text { lated } \\
\text { fre- } \\
\text { quency }\end{array}$ & $\begin{array}{l}\text { Band } \\
\text { type } \\
\text { pre- } \\
\text { dicted }\end{array}$ \\
\hline $\begin{array}{l}673 \\
685\end{array}$ & & & Doubtful & & \\
\hline 831 & $\left\{\begin{array}{l}811 \\
831 \\
849\end{array}\right.$ & very weak & $\begin{array}{c}\nu_{3}-\nu_{14} \\
\nu_{4} \\
\left(a_{1}\right)^{*}\end{array}$ & $\begin{array}{l}811 \\
806\end{array}$ & $\begin{array}{l}B \\
A\end{array}$ \\
\hline $\begin{array}{l}1274 \\
1311\end{array}$ & $\begin{array}{l}1267 \\
1302\end{array}$ & $\begin{array}{l}\text { med. weak } \\
\text { med. weak }\end{array}$ & & & \\
\hline $\begin{array}{l}1377 \\
1405\end{array}$ & $\begin{array}{l}1377 \\
1405\end{array}$ & $\begin{array}{l}\text { med. weak } \\
\text { med. weak }\end{array}$ & $\nu_{15}-\nu_{14}$ & 1376 & $C$ \\
\hline 1722 & $(2088$ & weak & $\begin{array}{l}\nu_{9}+\nu_{11} \\
\nu_{15}+\nu_{14}\end{array}$ & $\begin{array}{l}1737 \\
2114\end{array}$ & $\stackrel{A}{C}$ \\
\hline 2134 & $\left\{\begin{array}{l}2124 \\
2143 \\
2200\end{array}\right.$ & very weak & $\begin{array}{ll}\nu_{2} & \left(a_{1}\right)^{*}\end{array}$ & 2102 & $A$ \\
\hline 2217 & $\left\{\begin{array}{l}2215 \\
2230\end{array}\right.$ & very weak & $\nu_{7}+\nu_{17}$ & 2210 & $B$ \\
\hline 2353 & 2345 & strong & $\nu_{3}+\nu_{18}$ & 2354 & $A$ \\
\hline 3135 & 3135 & very weak & $\nu_{3}+\nu_{8}$ & 3168 & C \\
\hline 3670 & $\begin{array}{r}3600- \\
3700\end{array}$ & & $\begin{array}{l}\nu_{1}+\nu_{18} \\
\nu_{3}+\nu_{16}\end{array}$ & $\begin{array}{l}3697 \\
3700\end{array}$ & $A$ \\
\hline & & & $\nu_{2}+\nu_{17}$ & 3706 & $A$ \\
\hline 4040 & 4035 & very weak & $\nu_{2}+\nu_{8}$ & 4090 & $B$ \\
\hline 4250 & 4155 & weak & $\begin{array}{l}\nu_{1}+\nu_{17} \\
\nu_{6}+\nu_{17}\end{array}$ & $\begin{array}{l}4127 \\
4195\end{array}$ & $\begin{array}{l}A \\
B\end{array}$ \\
\hline & 4350 & weak & $\nu_{1}+\nu_{13}$ & 4380 & $B$ \\
\hline & 4473 & very weak & $\nu_{6}+v_{13}$ & 4448 & $A$ \\
\hline 4550 & & very weak & $\nu_{1}+\nu_{8}$ & 4511 & $C$ \\
\hline & $\begin{array}{l}4815 \\
5022\end{array}$ & $\begin{array}{l}\text { very weak } \\
\text { very weak }\end{array}$ & $\begin{array}{l}\nu_{2}+\nu_{12} \\
\nu_{1}+\nu_{16}\end{array}$ & $\begin{array}{l}4711 \\
5043\end{array}$ & $\begin{array}{l}B \\
C\end{array}$ \\
\hline 5150 & 5140 & weak & $\nu_{1}+\nu_{12}$ & 5132 & $B$ \\
\hline & 5210 & very weak & $\nu_{6}+\nu_{12}$ & 5200 & $A$ \\
\hline
\end{tabular}

* Isotopic molecule $\mathrm{B}^{11} \mathrm{~B}^{10} \mathrm{H}$.

these series of lines. The deviations listed in the tables give the mean values of the absolute deviations of the several frequencies calculated using the observed line positions, from the values computed with the equations fitted by a least-squares method to the plotted points. The method of selected points was used to deduce equations for the curves from which the positions of the band centers were determined.

For the type $C$ band at $972.7 \mathrm{~cm}^{-1}$, the band center corresponding to the heavier molecule lies at the lower frequency as expected, and the values for the rotational constant $(A-\widetilde{B})$ are larger. For the type $B$ band at $2608.6 \mathrm{~cm}^{-1}$ the results of the analysis are not as satisfactory in the case of the isotopic molecule $\mathrm{B}^{11} \mathrm{~B}^{10} \mathrm{H}_{6}$. The band center for the lighter molecule lies at higher frequency, but the values of the rotational constants come out to be somewhat larger, due perhaps to overlapping of the lines in the negative branch of the band.

The several combination relations for $K$ numbers from 3 to 8 or 9 in the band at $368.7 \mathrm{~cm}^{-1}$ all yield nearly constant values. Consequently simple averages were used for the values of these quantities from which the band center and the rotational constant $(A-\widetilde{B})$ in the upper and lower vibrational states were calculated. Data on this band fit the symmetric top approximation exceedingly well. The fact that the values of the rotational constants for the upper and lower states coincide
TABLE IV. Line positions in the type $A$ bands of diborane.

\begin{tabular}{|c|c|c|c|c|c|}
\hline \multicolumn{3}{|c|}{ Band at $2519.5 \mathrm{~cm}^{-1}$} & \multicolumn{3}{|c|}{ Band at $1173.3 \mathrm{~cm}^{-1}$} \\
\hline$J$ & $P$ branch & $R$ branch & $J$ & $P$ branch & $R$ branch \\
\hline \multirow{35}{*}{$\begin{array}{r}\mathbf{0} \\
\mathbf{1} \\
\mathbf{2} \\
3 \\
4 \\
5 \\
6 \\
7 \\
8 \\
9 \\
10 \\
11 \\
12 \\
13 \\
14 \\
15 \\
16 \\
17 \\
18 \\
19 \\
20 \\
21 \\
22 \\
23 \\
24 \\
25 \\
26 \\
27 \\
28 \\
29 \\
30 \\
31 \\
32 \\
33 \\
34\end{array}$} & & 2521.17 & 0 & & 1175.44 \\
\hline & & & 1 & & 1176.53 \\
\hline & 2517.29 & 2523.26 & 2 & 1171.17 & 1177.35 \\
\hline & 2516.10 & 2524.47 & 3 & 1170.21 & 1178.18 \\
\hline & 2514.97 & 2525.48 & 4 & 1168.86 & 1179.46 \\
\hline & 2513.76 & 2526.62 & 5 & 1167.69 & 1180.72 \\
\hline & 2512.66 & 2527.70 & 6 & 1166.57 & 1181.97 \\
\hline & 2511.43 & 2528.90 & 7 & 1165.40 & 1183.27 \\
\hline & 2510.08 & 2530.14 & 8 & 1164.25 & 1184.56 \\
\hline & 2508.97 & 2531.20 & 9 & 1163.13 & 1185.80 \\
\hline & 2507.83 & 2532.36 & 10 & 1161.99 & 1187.06 \\
\hline & 2506.78 & 2533.64 & 11 & 1160.71 & 1188.21 \\
\hline & 2505.57 & 2534.76 & 12 & 1159.60 & 1189.49 \\
\hline & 2504.44 & 2535.89 & 13 & 1158.44 & 1190.47 \\
\hline & 2503.36 & 2537.00 & 14 & 1157.36 & (1192.29) \\
\hline & 2502.08 & 2538.27 & 15 & 1156.21 & \\
\hline & 2500.86 & 2539.36 & 16 & 1155.11 & 1193.47 \\
\hline & 2499.67 & 2540 & 17 & 1154.04 & 1194.54 \\
\hline & 2498.54 & 2541.47 & 18 & 1152.86 & 1195.68 \\
\hline & 2497.27 & 2542.75 & 19 & 1151.84 & 1196.88 \\
\hline & 2496.01 & 2543.83 & 20 & 1150.64 & 1198.07 \\
\hline & 2494.84 & & 21 & 1149.65 & 1199.20 \\
\hline & 2493.70 & & 22 & 1148.46 & \\
\hline & 2492.38 & & 23 & 1147.55 & 1201.14 \\
\hline & 2491.19 & & 24 & 1146.44 & 1202.15 \\
\hline & 2490.04 & & 25 & 1145.40 & 1203.19 \\
\hline & 2488.99 & 2550.58 & 26 & 1144.22 & 1204.56 \\
\hline & 2487.59 & 2551.72 & 27 & 1142.95 & 1205.90 \\
\hline & 2486.33 & 2552.74 & 28 & & 1207.14 \\
\hline & 2485.24 & 2553.94 & 29 & 1140.76 & 1208.35 \\
\hline & 2484.08 & & 30 & & 1209.49 \\
\hline & 2482.95 & 2556.52 & 31 & 1138.37 & 1210.54 \\
\hline & \multirow{3}{*}{\multicolumn{2}{|c|}{$\begin{array}{l}2481.56 \\
2480.41 \\
2479.16\end{array}$}} & \multirow{3}{*}{\multicolumn{3}{|c|}{$\begin{array}{l}\text { Maxima in } Q \text { branch at } \\
1173.16 \text { and } 1174.33\end{array}$}} \\
\hline & & & & & \\
\hline & & & & & \\
\hline \multicolumn{3}{|c|}{$\begin{array}{c}\text { Maxima in } Q \text { branch at } \\
2518.94 \text { and } 2520.23\end{array}$} & & & \\
\hline
\end{tabular}

within the probable errors indicates very little interaction between rotation and vibration.

Analysis over the same range of $K$ values is not so satisfactory for the type $C$ band at $1988.0 \mathrm{~cm}^{-1}$. While the resolved lines extend to much higher and lower values of frequency than those represented by $K$ numbers of 8 or 9 , beyond these numbers the stronger lines no longer have the appropriate nearly uniform spacing observed in the high frequency branch. Possible causes for this effect include: (1) the presence of lines due to water vapor which are more intense and numerous than in the high frequency branch, and (2) the overlapping of the much stronger band with center at $1857 \mathrm{~cm}^{-1}$.

\section{CONCLUSION}

Measurements in the infra-red absorption spectrum of diborane of the rotational fine structure in two bands of each type characteristic of asymmetric top molecules have lead to reliable values for the centers of these bands and values for rotational constants $(A-\widetilde{B})$ and $\widetilde{B}$. All observations and results are consistent with the conclusion that diborane has the bridge structure and belongs to the same symmetry point group, $V_{h}$, as ethylene. Nearly all observed absorption bands seem 
TABLE V. Line positions in the $2608.6 \mathrm{~cm}^{-1}$ band of diborane.*

\begin{tabular}{|c|c|c|c|c|c|c|c|}
\hline$K$ & $\begin{array}{c}\text { Negative } \\
\text { branch }\end{array}$ & $K$ & $\begin{array}{c}\text { Positive } \\
\text { branch }\end{array}$ & $K$ & $\begin{array}{c}\text { Negative } \\
\text { branch }\end{array}$ & $K$ & $\begin{array}{l}\text { Positive } \\
\text { branch }\end{array}$ \\
\hline & 2608.72 & & 2611.42 & 10 & $2568.10 \mathrm{~s}$ & 10 & $2650.22 \mathrm{~s}$ \\
\hline \multirow{2}{*}{1} & 2607.95 & 1 & 2612.27 & & 2566.19 & & 2651.86 \\
\hline & 2604.60 & & $2617.18 \mathrm{~s}$ & & $\begin{array}{l}2505.80 \\
2565.37\end{array}$ & 11 & $2654.12 \mathrm{~s}$ \\
\hline \multirow[t]{3}{*}{2} & $2603.68 \mathrm{~s}$ & 2 & $2619.06 \mathrm{~s}$ & & 2564.68 & & 2655.22 \\
\hline & 2602.15 & & 2619.92 & 11 & $2563.56 \mathrm{~s}$ & & 2657.19 \\
\hline & $2600.64 \mathrm{~s}$ & & 2620.55 & & 2562.39 & 12 & 2658.48 \\
\hline \multirow[t]{5}{*}{3} & $2598.48 \mathrm{~s}$ & & 2621.74 & & 2560.22 & & 2659.64 \\
\hline & 2597.30 & 3 & $2622.78 \mathrm{~s}$ & 12 & $2559.44 \mathrm{~s}$ & & 2660.77 \\
\hline & 2596.59 & & $\begin{array}{l}2623.91 \\
2625\end{array}$ & & 2558.33 & & 2662.77 \\
\hline & $2595.62 \mathrm{~s}$ & & 2625.50 & & 2557.22 & & 2663.41 \\
\hline & 2595.09 & 4 & $2626.97 \mathrm{~s}$ & & 2555.70 & & 2663.99 \\
\hline \multirow{2}{*}{4} & $2593.91 \mathrm{~s}$ & & 2627.55 & & 2554.97 & & 2665.49 \\
\hline & $\begin{array}{l}2592.44 \\
2591.17\end{array}$ & & $\begin{array}{l}2628.40 \\
2629.75\end{array}$ & & $\begin{array}{l}2548.88 \\
2547.70\end{array}$ & & $\begin{array}{l}2666.31 \\
2668.09\end{array}$ \\
\hline \multirow[t]{2}{*}{5} & $2589.72 \mathrm{~s}$ & & 2630.27 & & 2546.61 & & 2669.27 \\
\hline & $\begin{array}{l}2588.40 \\
2586.93 \\
2586.27\end{array}$ & 5 & $\begin{array}{l}2631.08 \mathrm{~s} \\
2632.38 \\
2633.27 \mathrm{~s}\end{array}$ & & $\begin{array}{l}2545.36 \\
2544.45\end{array}$ & & $\begin{array}{l}2670.41 \\
2671.61 \\
2672.64\end{array}$ \\
\hline \multirow[t]{3}{*}{6} & $2585.39 \mathrm{~s}$ & 6 & $2634.86 \mathrm{~s}$ & & & & 2673.44 \\
\hline & 2582.86 & & 2635.71 & & & & 2674.69 \\
\hline & 2581.93 & & 2636.58 & & & & 2675.84 \\
\hline \multirow[t]{2}{*}{7} & $2581.18 \mathrm{~s}$ & & 2638.16 & & & & 2676.93 \\
\hline & $\begin{array}{l}2578.91 \\
2577.73 \mathrm{~s}\end{array}$ & 7 & $\begin{array}{l}2638.88 \mathrm{~s} \\
2640.42\end{array}$ & & & & $\begin{array}{l}2677.86 \\
2679.19\end{array}$ \\
\hline \multirow[t]{4}{*}{8} & $2576.68 \mathrm{~s}$ & & 2641.77 & & & & 2680.04 \\
\hline & 2575.23 & 8 & $2642.79 \mathrm{~s}$ & & & & 2680.93 \\
\hline & 2573.42 & & 2643.27 & & & & 2682.39 \\
\hline & 2572.68 & & 2644.22 & & & & 2683.24 \\
\hline 9 & $2572.28 \mathrm{~s}$ & & 2645.14 & & & & 2686.71 \\
\hline & 2570.95 & 9 & $2646.39 \mathrm{~s}$ & & & & 2687.65 \\
\hline & 2569.89 & & 2647.77 & & & & 2688.73 \\
\hline & 2569.14 & & 2648.37 & & & & 2689.67 \\
\hline & 2568.54 & & & & & & \\
\hline
\end{tabular}

* The more intense lines are marked $\mathrm{s}$.

TABLE VI. Line positions in the $368.7 \mathrm{~cm}^{-1}$ band.

\begin{tabular}{ccc}
\hline$K$ & ${ }^{P_{Q_{K}}}$ & ${ }^{R_{Q_{K}}}$ \\
\hline 0 & 366.10 & 370.94 \\
1 & 362.96 & 374.96 \\
2 & 360.47 & 376.92 \\
& 358.28 & 379.18 \\
3 & 354.36 & 383.04 \\
4 & 350.21 & 387.30 \\
5 & 346.22 & 391.38 \\
6 & 341.95 & 395.34 \\
7 & 337.73 & 399.50 \\
8 & 333.62 & 403.55 \\
9 & & 407.85 \\
10 & & 411.84 \\
& & 416.12 \\
& & 419.63 \\
& & 423.47 \\
& & 425.33 \\
& & 427.81 \\
& & 430.52 \\
\hline
\end{tabular}

reasonably accounted for on the basis of the assignments of fundamental frequencies and combinations thereof. However, observation under high resolution in vacuum is needed to clear up uncertainties in the regions $1250-1900 \mathrm{~cm}^{-1}$ and $3600-3750 \mathrm{~cm}^{-1}$.

From the analysis of the rotational fine structure on the symmetric top approximation, average values of the rotational constants in the ground states have been
TABLE VII. Line positions in the $1988.0 \mathrm{~cm}^{-1}$ band.*

\begin{tabular}{|c|c|c|c|}
\hline $\begin{array}{c}\text { Negative } \\
\text { branch }\end{array}$ & $\begin{array}{l}\text { Positive } \\
\text { branch }\end{array}$ & $\begin{array}{c}\text { Negative } \\
\text { branch }\end{array}$ & $\begin{array}{c}\text { Positive } \\
\text { branch }\end{array}$ \\
\hline 1987.41 & 1994.05 & 1946.46 & 2048.98 \\
\hline 1986.84 & 1994.90 & 1944.71 & $2050.10 \mathrm{~s}$ \\
\hline 1986.34 & 1995.92 & 1942.58 & 2051.52 \\
\hline $1985.82 \mathrm{~s}$ & $1997.47 \mathrm{~s}$ & 1941.42 & $2052.84 \mathrm{~s}$ \\
\hline 1985.22 & 1998.32 & 1940.17 & 2053.82 \\
\hline 1984.71 & & $1939.91 \mathrm{~s}$ & 2054.97 \\
\hline 1984.22 & $2001.24 \mathrm{~s}$ & 1939.20 & $2056.29 \mathrm{~s}$ \\
\hline 1983.02 & 2002.22 & $1938.00 \mathrm{~s}$ & 2057.23 \\
\hline 1982.53 & 2003.53 & $1937.06 \mathrm{~s}$ & 2058.57 \\
\hline 1981.63 & 2004.52 & 1935.89 & 2059.76 \\
\hline $1981.33 \mathrm{~s}$ & 2005.06 & 1935.18 & $2062.16 \mathrm{~s}$ \\
\hline 1980.85 & $2006.11 \mathrm{~s}$ & 1934.66 & 2063.20 \\
\hline 1979.56 & & 1933.94 & 2066.95 \\
\hline 1978.25 & & 1931.80 & 2067.72 \\
\hline $1977.37 \mathrm{~s}$ & $2010.06 \mathrm{~s}$ & 1930.79 & 2069.15 \\
\hline 1976.88 & 2012.05 & $1929.98 \mathrm{~s}$ & 2070.26 \\
\hline 1975.16 & 2013,07 & 1928.75 & 2071.32 \\
\hline 1974.17 & $2013.94 \mathrm{~s}$ & 1927.72 & 2072.54 \\
\hline $1973.08 \mathrm{~s}$ & 2015.53 & 1926.56 & 2076.06 \\
\hline 1971.72 & 2016.86 & 1925.65 & 2078.33 \\
\hline 1970.76 & 2017.66 & & 2080.56 \\
\hline 1970.27 & 2019.18 & & 2082.32 \\
\hline 1969.20 & 2020.45 & & \\
\hline 1968.69 & $2021.31 \mathrm{~s}$ & & \\
\hline 1967.64 & 2023.15 & & \\
\hline 1966.34 & 2024.39 & & \\
\hline 1964.94 & $2025.15 \mathrm{~s}$ & & \\
\hline 1964.29 & 2026.86 & & \\
\hline $1963.28 \mathrm{~s}$ & 2028.09 & & \\
\hline 1962.11 & $2028.97 \mathrm{~s}$ & & \\
\hline 1960.36 & 2030.28 & & \\
\hline $1959.41 \mathrm{~s}$ & 2031.03 & & \\
\hline 1958.18 & 2031.73 & & \\
\hline 1957.02 & $2032.53 \mathrm{~s}$ & & \\
\hline 1955.96 & 2034.51 & & \\
\hline & $2036.25 \mathrm{~s}$ & & \\
\hline $1953.84 \mathrm{~s}$ & 2037.77 & & \\
\hline 1952.35 & $2039.77 \mathrm{~s}$ & & \\
\hline 1951.40 & 2042.90 & & \\
\hline 1950.30 & 2045.59 & & \\
\hline $1949.15 \mathrm{~s}$ & $2046.69 \mathrm{~s}$ & & \\
\hline 1947.80 & 2047.74 & & \\
\hline
\end{tabular}

* The more intense lines are marked s. Strong lines in central maximum at $1990.59,1991.28$, and $1991.97 \mathrm{~cm}^{-1}$.

deduced as follows: $\widetilde{B}^{\prime \prime}=0.582 \pm 0.002 \mathrm{~cm}^{-1}$, and $\left(A^{\prime \prime}-\widetilde{B}^{\prime \prime}\right)=2.080 \pm 0.005 \mathrm{~cm}^{-1}$. From the value for $\widetilde{B}^{\prime \prime}$ the product of the two larger moments of inertia divided by their sum is $48.1 \times 10^{-40} \mathrm{~g} \mathrm{~cm}^{2}$. The value of $A^{\prime \prime}$ yields for the minimum moment of inertia a magnitude of $10.5 \times 10^{-40} \mathrm{~g} \mathrm{~cm}^{2}$. Electron diffraction data interpreted on the non-planar bridge model predict the values of $49.2 \times 10^{-40} \mathrm{~g} \mathrm{~cm}^{2}$ and $10.7 \times 10^{-40}$ $\mathrm{g} \mathrm{cm}^{2}$, respectively, for $\mathrm{B}_{2}{ }^{11} \mathrm{H}_{6}$.

The appearance of the type $B$ band at $368.7 \mathrm{~cm}^{-1}$ with a gap or trough at the band center is interpreted as spectroscopic evidence that the diborane molecule is not planar. If the bridge hydrogens were in the same plane as the four terminal hydrogens, the out-of-theplane bending vibration involving the bridge hydrogens would cause variation of the electric moment along the axis of greatest moment of inertia. A type $C$ band would then be expected for the lowest frequency band.

The comparative regularity observed in the so-called perpendicular bands, type $B$ and type $C$, also is evi- 
TABLE VIII. Line positions in the $972.7 \mathrm{~cm}^{-1}$ band of diborane.*

\begin{tabular}{|c|c|c|c|}
\hline $\begin{array}{c}\text { Negative } \\
\text { branch } \\
\mathrm{cm}^{-1}\end{array}$ & $\begin{array}{l}\text { Positive } \\
\text { branch } \\
\mathrm{cm}^{-1}\end{array}$ & $\begin{array}{c}\text { Negative } \\
\text { branch } \\
\mathrm{cm}^{-1}\end{array}$ & $\begin{array}{l}\text { Positive } \\
\text { branch } \\
\mathrm{cm}^{-1}\end{array}$ \\
\hline 971.22 & 976.34 & 930.66 & 1016.14 \\
\hline 969.84 & 977.14 & 930.10 & 1016.73 \\
\hline 968.47 & 977.94 & 929.42 & 1017.23 \\
\hline 967.06 & 978.86 & 928.66 & 1017.76 \\
\hline 965.75 & 979.53 & 928.14 & 1018.33 \\
\hline 965.18 & 979.97 & 927.53 & 1018.88 \\
\hline 964.43 & 981.05 & 926.82 & 1019.43 \\
\hline 964.07 & 982.31 & 925.55 & 1020.58 \\
\hline 963.70 & $983.31 \mathrm{~s}$ & 924.66 & 1021.16 \\
\hline $962.45 \mathrm{~s}$ & 984.58 & 924.29 & 1021.69 \\
\hline 960.77 & 985.13 & 923.02 & 1022.12 \\
\hline 959.17 & 985.80 & 921.80 & 1022.75 \\
\hline $958.13 \mathrm{~s}$ & 986.49 & 920.46 & 1023.21 \\
\hline 956.74 & 987.05 & 919.34 & 1023.74 \\
\hline 955.50 & $987.45 \mathrm{~s}$ & 917.93 & 1024.15 \\
\hline $954.12 \mathrm{~s}$ & 988.95 & 916.67 & 1024.88 \\
\hline 952.92 & 989.72 & 915.44 & 1025.42 \\
\hline 951.63 & 990.82 & 914.34 & 1025.98 \\
\hline 951.22 & $991.64 \mathrm{~s}$ & 913.02 & 1027.08 \\
\hline $950.09 \mathrm{~s}$ & 992.90 & & \\
\hline 949.84 & 993.69 & 911.78 & 1027.61 \\
\hline 949.11 & $994.79 \mathrm{~s}$ & 910.46 & 1028.13 \\
\hline 948.70 & 995.82 & 909.21 & 1028.73 \\
\hline 947.85 & 997.09 & & \\
\hline 947.48 & 998.31 & 907.81 & 1029.77 \\
\hline $946.13 \mathrm{~s}$ & 998.72 & 906.62 & 1030.60 \\
\hline 945.03 & 999.47 & 905.31 & 1031.62 \\
\hline 943.98 & $1000.09 \mathrm{~s}$ & 904.07 & 1032.91 \\
\hline 943.57 & 1001.12 & 902.79 & 1034.13 \\
\hline 942.94 & 1001.67 & 901.50 & 1035.16 \\
\hline $942.07 \mathrm{~s}$ & 1002.21 & 900.22 & 1036.09 \\
\hline 940.99 & 1003.23 & 899.58 & 1037.17 \\
\hline 939.41 & $1004.28 \mathrm{~s}$ & 898.95 & 1038.46 \\
\hline 938.86 & 1005.43 & 897.69 & 1039.56 \\
\hline $938.26 \mathrm{~s}$ & 1006.50 & 897.17 & 1040.69 \\
\hline 937.70 & 1007.58 & 896.47 & 1041.64 \\
\hline 937.08 & $1008.58 \mathrm{~s}$ & 895.14 & 1042.73 \\
\hline 935.80 & 1009.83 & 893.87 & 1043.87 \\
\hline 935.31 & 1010.86 & 893.05 & 1044.96 \\
\hline $934.58 \mathrm{~s}$ & 1011.91 & 892.68 & 1045.97 \\
\hline 933.73 & $1012.94 \mathrm{~s}$ & 891.36 & 1047.10 \\
\hline & 1013.99 & 890.16 & 1048.27 \\
\hline \multirow{5}{*}{932.00} & 1015.13 & 888.91 & 1049.41 \\
\hline & & 887.74 & 1050.54 \\
\hline & & & 1051.61 \\
\hline & & & 1052.64 \\
\hline & & & $\begin{array}{l}1053.74 \\
1055.01\end{array}$ \\
\hline
\end{tabular}

* The more intense lines are marked s. Strong lines in central maximum at $972.66,973.79$, and $975.13 \mathrm{~cm}^{-1}$.

dence that the molecule is non-planar, since this configuration would be expected to be more symmetric, that is the two larger moments of inertia would be more nearly equal, than for the planar model.

Before the molecular dimensions can be uniquely determined, it will be necessary to resolve and analyze absorption bands of $\mathrm{B}_{2} \mathrm{D}_{6}$ as well as $\mathrm{B}_{2}{ }^{10} \mathrm{H}_{6}$, both of which compounds can be produced and undoubtedly can be handled with no more difficulty than experienced with ordinary diborane. The values of rotational constants deduced for $\mathrm{B}^{11} \mathrm{~B}^{10} \mathrm{H}_{6}$ are probably not satisfactory for calculations of dimensions.

Lack of agreement between the experimental observations and the results of the normal coordinate treat-
TABLE IX. Line positions in the type $C$ bands.

\begin{tabular}{rrrrrr}
\hline & \multicolumn{2}{c}{ Band at 1988.0 cm-1 } & \multicolumn{3}{c}{ Band at 972.7 $\mathrm{cm}^{-1}$} \\
$K$ & ${ }^{P_{Q_{K}}}$ & ${ }^{R_{Q_{K}}}$ & \multicolumn{1}{c}{$K$} & ${ }^{P_{Q_{K}}}$ & ${ }^{R_{Q_{K}}}$ \\
\hline 0 & & 1990.59 & & & \\
1 & 1985.82 & 1994.90 & 1 & 971.22 & 978.86 \\
2 & 1981.63 & 1998.32 & 2 & 967.06 & 983.31 \\
3 & 1977.37 & 2002.22 & 3 & 962.45 & 987.45 \\
4 & 1973.08 & 2006.11 & 4 & 958.23 & 991.64 \\
5 & 1968.69 & 2010.06 & 5 & 954.12 & 995.82 \\
6 & 1964.29 & 2013.94 & 6 & 950.09 & 1000.09 \\
7 & 1960.36 & 2017.66 & 7 & 946.13 & 1004.28 \\
8 & 1955.96 & 2021.31 & 8 & 942.07 & 1008.58 \\
9 & 1951.40 & 2025.15 & 9 & 938.26 & 1012.94 \\
10 & & 2028.97 & 10 & 934.58 & 1017.23 \\
11 & & 2032.53 & 11 & 930.66 & 1021.69 \\
12 & & 2036.25 & 12 & 926.82 & 1025.98 \\
13 & & 2039.77 & 13 & 923.02 & 1030.63 \\
& & & & & \\
\hline
\end{tabular}

TABLE X. Summary of results on symmetric top approximation.

\begin{tabular}{|c|c|c|c|c|c|c|c|}
\hline \multicolumn{8}{|c|}{ Type $A$ bands } \\
\hline $\begin{array}{c}\text { Region } \\
\quad \mu \\
\end{array}$ & $\begin{array}{c}\text { Band } \\
\text { center } \\
\mathrm{cm}^{-1}\end{array}$ & $\begin{array}{c}\text { Average } \\
\text { devia- } \\
\text { tion }\end{array}$ & $\begin{array}{c}\text { Absorption } \\
\text { maximum } \\
\mathrm{cm}^{-1}\end{array}$ & $\begin{array}{r}4 \tilde{B}^{\prime \prime} \\
\mathrm{cm}^{-1}\end{array}$ & $\begin{array}{c}\text { Average } \\
\text { devia- } \\
\text { tion }\end{array}$ & $\begin{array}{c}4 \tilde{B}^{\prime} \\
\mathrm{cm}^{-1}\end{array}$ & $\begin{array}{c}\text { Average } \\
\text { devia- } \\
\text { tion }\end{array}$ \\
\hline 3.97 & 2 & 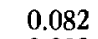 & 2 & 2.332 & 0.005 & 36 & 08 \\
\hline & & & 1173.16 & 2.316 & 0.025 & 2.265 & .025 \\
\hline \multicolumn{8}{|c|}{ Type $B$ bands } \\
\hline$\underset{\mu}{\text { Region }}$ & $\begin{array}{c}\text { Band } \\
\text { center } \\
\mathrm{cm}^{-1}\end{array}$ & $\begin{array}{c}\text { Average } \\
\text { devia- } \\
\text { tion }\end{array}$ & $\begin{array}{l}\text { Absorption } \\
\text { minimum } \\
\mathrm{cm}^{-1}\end{array}$ & $\begin{array}{c}A^{\prime \prime}-\bar{B}^{\prime \prime} \\
\mathrm{cm}^{-1}\end{array}$ & $\begin{array}{c}\text { Average } \\
\text { devia- } \\
\text { tion }\end{array}$ & $\begin{array}{l}A^{\prime}-\tilde{B}^{\prime} \\
\mathrm{cm}^{-1}\end{array}$ & $\begin{array}{c}\text { Average } \\
\text { devia- } \\
\text { tion }\end{array}$ \\
\hline 3.83 & 4 & & & & & & \\
\hline & 2609.92 & 0.175 & 2610 & 2.138 & 0.013 & 2.108 & 0.009 \\
\hline 27.12 & 368.68 & 0.059 & 368.23 & 2.058 & 0.003 & 2.056 & 0.004 \\
\hline \multicolumn{8}{|c|}{ Type $C$ bands } \\
\hline $\operatorname{Region}_{\mu}$ & $\begin{array}{l}\text { Band } \\
\text { center } \\
\mathrm{cm}^{-1}\end{array}$ & $\begin{array}{c}\text { Average } \\
\text { devia- } \\
\text { tion }\end{array}$ & $=\underset{\text { maximum }_{\mathrm{cm}^{-1}}^{\text {Absorption }}}{ }$ & $\begin{array}{c}A^{\prime \prime}-\bar{B}^{\prime \prime} \\
\mathrm{cm}^{-1}\end{array}$ & $\begin{array}{l}\text { Average } \\
\text { devia- } \\
\text { tion }\end{array}$ & $\begin{array}{l}A^{\prime}-\tilde{B}^{\prime} \\
\mathrm{cm}^{-1}\end{array}$ & $\begin{array}{c}\text { Average } \\
\text { devia- } \\
\text { tion }\end{array}$ \\
\hline 5.02 & 1988.00 & & 199 & 2.1 & 0.009 & 2.071 & 0.006 \\
\hline 10.28 & & & & & & & \\
\hline ( ) & 975.2 & 0.097 & 975.13 & 2.054 & 0.006 & 2.065 & 0.009 \\
\hline
\end{tabular}

a Assigned to the molecule $\mathrm{B}^{11} \mathrm{~B}^{10 \mathrm{H}} 6$.

ment of Bell and Longuet-Higgins ${ }^{2}$ indicates the need for a more rigorous theoretical study of the vibrations of the bridge model for the type molecule $X_{2} Y_{6}$. The experimental results already obtained can then be used to deduce reliable values for the force constants of diborane.

\section{ACK NOWLEDGMENT}

It is a pleasure to acknowledge our indebtedness to the Chemistry Department of the University of Chicago for the sample of diborane. Special thanks are due Mr. A. C. Bond, then of the Chemistry Department, University of Michigan, for procuring the diborane sample, and for much assistance in purifying and handling the gas. To Dr. L. G. Smith, formerly of this laboratory, appreciation is due for his contributions to the design of an amplifier for automatic recording of infra-red absorption bands. 